\title{
I58. THE VITAMIN $B_{2}$ COMPLEX OF LIVER: THE IDENTITY OF THE LIVER FILTRATE FACTOR WITH PANTOTHENIC ACID
}

\author{
By B. LYTHGOE, T. F. MACRAE, R. H. STANLEY, \\ A. R. TODD AND C. ELIZABETH WORK \\ From the Chemistry Department, University of Manchester and the Division \\ of Nutrition, Lister Institute
}

(Received 19 August 1940)

IN a previous communication [Macrae et al. 1939] we described the preparation. from liver extracts of highly potent concentrates of a nutritional factor for rats to which we applied the name "liver filtrate factor" [cf. Edgar et al. 1938]. At that time we drew attention to the similarity in properties between this factor and pantothenic acid [Williams et al. 1938; 1939] and discussed the possibility that the two might ultimately prove to be identical. Pantothenic acid was then known to be the $\beta$-alanide of a readily lactonizable hydroxy-acid of unknown constitution and had been shown to be identical with the chick antidermatitis factor [Woolley et al. 1939, 1, 2; Jukes, 1939]. The suggestion that this acid was concerned in rat growth was supported to some extent by other evidence; for example, impure concentrates of pantothenic acid were shown to possess growthstimulating properties for rats [Subbarow \& Hitchings, 1939; Oleson et al. 1939].

Preliminary experiments showed that the active material present in our concentrates contained an amide linkage. Using micro-titration methods of the Willstätter-Waldschmidt-Leitz type it was found that destruction of the factor by hydrolysis with dilute alkali caused an increase in the titre of the acid material with alcoholic $\mathrm{NaOH}$, whilst the titre after hydrolysis with dilute acid remained unchanged; this is in agreement with the production during hydrolysis of a readily lactonizable acidic fragment. It was further found that $\beta$-alanine could be isolated from hydrolysed concentrates of our factor as its $\beta$-naphthalenesulphonyl derivative, although from the mode of preparation no free $\beta$-alanine could have been present in the unhydrolysed concentrate. When the lactone portion from these hydrolysed concentrates (itself completely inactive in rats in daily doses of about $2 \mathrm{mg}$.) was coupled with $\beta$-alanine, using the method employed by Woolley et al. [1939, 2] for regeneration of the chick anti-dermatitis factor, the reconstituted material was found to be fully active when fed to rats in daily doses of about $1 \mathrm{mg}$. These results correspond with those obtained by Woolley et al. [1939, 1, 2] with the chick factor. We also commenced, in common with many other investigators [Subbarow \& Rane, 1939; Babcock \& Jukes, 1940; Reichstein \& Grüssner, $\left.1940^{*}\right]$, the synthesis of $\beta$-alanides of various dihydroxyvaleric acids, partly in the hope of obtaining an active substance but more especially with a view to studying the chemical behaviour of mixtures of these compounds. Of the compounds prepared $\gamma: \delta$-dihydroxyvaleryl- $\beta$-alanine has not hitherto been described; details of the preparation of its methyl ester are given in the experimental section.

* Through the kindness of Prof. Reichstein we were privileged to see the manuscript of a paper on this subject which was submitted to the Helvetica Chimica Acta May 1940. The actual published paper we have not up to the present been able to obtain.

Biochem. 1940, 34

( 1335 ) 
While these experiments were in progress the identification of pantothenic acid as $\alpha: \gamma$-dihydroxy- $\beta: \beta$-dimethylbutyryl- $\beta$-alanine and its synthetic preparation were announced in an important communication by Williams \& Major [1940]. Through the kindness of Dr Major of Merck and Co., Inc., to whom we are deeply indebted, we were enabled to test the activity of a specimen of the synthetic material on our rats. The optimal daily dose for a rat we found to be contained in about $50 \mu \mathrm{g}$. of the synthetic dextrorotatory material, this supplement supporting, under our experimental conditions, a growth of about $16 \mathrm{~g}$. per week, equivalent to the response evoked by our liver filtrate factor. Rats receiving a daily supplement of $100 \mu \mathrm{g}$. pantothenic acid plus additional liver filtrate factor did not increase in body-weight significantly more rapidly than did animals receiving pantothenic acid or liver filtrate factor alone, i.e. liver filtrate factor and pantothenic acid can replace each other but have no supplementary effect and are therefore biologically identical. It would therefore appear that our purest preparation of liver filtrate factor, which was active in a daily dose of $180 \mu \mathrm{g}$. [Macrae et al. 1939], must have contained about $25 \%$ pantothenic acid.

Evidence has already been published from these laboratories [El Sadr et al. 1939] that our crude liver extracts contain at least three factors of the vitamin $B_{2}$ complex which are required to ensure maximal growth in rats receiving as supplements the already well-established members of this complex, viz. riboflavin, nicotinamide and vitamin $B_{6}$. The first of these unknown factors, which we have been accustomed to designate for our own convenience "factor $\alpha$ " or "liver filtrate factor", is characterized by its extractability from acid aqueous solutions by amyl alcohol, its failure to be adsorbed by fuller's earth at acid reactions, and its lability to acid and alkali; the identity of this factor with pantothenic acid has been fully established in this paper. Our second factor- "factor $\beta$ "is contained in that portion of liver extract which, at $p H \mathbf{H}$, is neither adsorbed by fuller's earth nor extracted with amyl alcohol. That it is a single growth factor we have as yet no definite proof, but its biological entity cannot be doubted. When it is supplied to rats receiving optimal supplements of factor $\alpha$ (pantothenic acid) a markedly higher growth-rate is observed. Since these results were published papers from other laboratories have appeared which afford further independent evidence of the existence in liver and other materials of a factor distinct from pantothenic acid which is not extracted from acid aqueous solutions by organic solvents [e.g. Hitchings \& Subbarow, 1939; Mohammad et al. 1940; Hoffer \& Reichstein, 1939; Kringstad \& Lunde, 1939; Black et al. 1940]. It is this material to which Black et al. [1940] now apply the term "factor. $W$ ", a designation formerly applied to a mixture of factors which included pantothenic acid and vitamin $\mathrm{B}_{6}$.

We have now obtained further evidence that our third factor-factor $\gamma$ is a biological entity. Rats receiving, as source of the unidentified $B_{2}$-vitamins, acid-autoclaved whole extract of liver together with concentrates of factor $\alpha$ and factor $\beta$. show a growth rate of about 35-40 g. per week as compared with about $20 \mathrm{~g}$. per week with acid-autoclaved whole extract of liver, $15 \mathrm{~g}$. per week with concentrates of factor $\beta$ and about $30 \mathrm{~g}$. with concentrates of both factors $\alpha$ and $\beta$. There must therefore be at least one further factor $(\gamma)$ present in acidautoclaved whole liver extracts. Details of these experiments will be published later. Whether these three factors $\alpha, \beta$ and $\gamma$ are together sufficient to produce optimal growth in rats receiving supplements of aneurin, riboflavin and vitamin $B_{6}$ we wish at present to leave an open question. Experiments designed to test this and to effect the purification and isolation of factors $\beta$ and $\gamma$ are at present in progress. 


\section{EXPERIMENTAL}

\section{Titration experiments}

The results of a series of microtitration experiments on a typical liver filtrate factor concentrate (concentrate 45 , containing 1 rat day dose in $0.72 \mathrm{mg}$.) are set out in Table 1.

\section{Table 1}

$\begin{array}{lcc} & \begin{array}{c}\text { Wt. of } \\ \text { concentrate } \\ \mathrm{mg} .\end{array} & \begin{array}{c}\text { Total NaOH } \\ \text { required for } \\ \text { neutralization }\end{array} \\ \begin{array}{c}\text { (g.-equivalents } \times 10^{-5} \text { ) } \\ \text { Untreated concentrate, titrated in aqueous } \\ \text { solution }\end{array} & 6.773 & 3.16 \\ \begin{array}{c}\text { Untreated concentrate, titrated in alcoholic } \\ \text { solution }\end{array} & 6.773 & 3.29 \\ \begin{array}{c}\text { Concentrate hydrolysed by alkali, the hydro- } \\ \text { lysis products titrated in aqueous solution }\end{array} & 6.773 & 3.40 \\ \begin{array}{c}\text { Concentrate hydrolysed by alkali, the hydro- } \\ \text { lysis products titrated in alcoholic solution }\end{array} & 6.773 & 5.43 \\ \begin{array}{c}\text { Concentrate hydrolysed by acid, the hydrolysis } \\ \text { products titrated in aqueous solution }\end{array} & 6.773 & 2.64 \\ \begin{array}{c}\text { Concentrate hydrolysed by acid, the hydrolysis } \\ \text { products titrated in alcoholic solution }\end{array} & 6.773 & 3.33\end{array}$

These results lead to the following conclusions: $(a)$ the concentrate contains a mixture of acidic materials with an approximate mean equivalent of 214 ; (b) the very small difference between the titre of the concentrate in aqueous and alcoholic solutions indicates the presence of only small quantities of basic nitrogen; $(c)$ the titre of the concentrate after hydrolysis with alkali shows a large increase over that of the original concentrate when titration is carried out in solution in alcohol of concentration $>97 \%$, but little increase is noted if the titrations are carried out in aqueous solution; this indicates the presence in the concentrate of material of an amide nature, the basic portion liberated from it on hydrolysis being of the amino-acid type; $(d)$ the acidic portion of the amide material must be readily lactonizable, since on hydrolysis with acid the titre of the product in aqueous solution shows a decrease, whereas that in alcoholic solution remains unchanged.

\section{Isolation of $\beta$-naphthalenesulphonyl- $\beta$-alanine}

A portion (2.4 g.) of liver filtrate factor concentrate 45 (containing 1 rat day dose in $0.72 \mathrm{mg}$.) was heated to $100^{\circ}$ for $2 \mathrm{hr}$. with $N \mathrm{H}_{2} \mathrm{SO}_{4}(100 \mathrm{ml}$.). After cooling, the solution was extracted 6 times with ethyl acetate (100 ml.). The aqueous acidic phase was freed from sulphate ions with barium hydroxide, evaporated to dryness and treated with conc. $\mathrm{HCl}(30 \mathrm{ml}$.$) . Excess acid was$ removed in vacuo and the dry residue extracted with $95 \%$ ethyl alcohol $(2 \times 100 \mathrm{ml}$.); the alcoholic extracts on evaporation yielded an oil. This was taken up in water $(200 \mathrm{ml}$.) and freed from chloride ions by shaking for $1 \mathrm{hr}$. with a suspension of silver oxide (from $15 \mathrm{~g}$. $\mathrm{AgNO}_{3}$ ), the excess of silver ions then being removed by $\mathrm{H}_{2} \mathrm{~S}$. After filtration the solution was concentrated to $8 \mathrm{ml}$. and a portion $(2 \mathrm{ml}$.) treated with alkali and shaken with an ethereal solution of $\beta$-naphthalenesulphonyl chloride (250 mg. in $15 \mathrm{ml}$. ether) as described by Weinstock et al. [1939]. On acidification of the aqueous layer $\beta$-naphthalenesulphonyl- $\beta$-alanine separated as white plates which after 3 
recrystallizations from hot water had M.P. 134:5-135.5 ${ }^{\circ}$. An authentic specimen in the same bath had M.P. $135 \cdot 5-136 \cdot 5^{\circ}$ and a mixture of approximately equal amounts of both materials melted at $135 \cdot 5-136 \cdot 5^{\circ}$. (Found: $\mathrm{C}, 55 \cdot 7 ; \mathrm{H}, 4 \cdot 7$; $\mathrm{N}, 4.9 \%$; calc. for $\mathrm{C}_{13} \mathrm{H}_{13} \mathrm{O}_{4} \mathrm{~N}: \mathrm{C}, 55 \cdot 8 ; \mathrm{H}, 4 \cdot 7 ; \mathrm{N}, 5 \cdot 0 \%$.)

\section{Reconstitution of pantothenic acid}

The method used was analogous to that described by Woolley et al. [1939, 2]. Liver filtrate factor concentrate 48 (13.08 g.) was heated to $100^{\circ}$ with $\mathrm{N} \mathrm{H}_{2} \mathrm{SO}_{4}$ $(200 \mathrm{ml}$.) for $2 \mathrm{hr}$. After cooling, the solution was adjusted to $p \mathrm{H} \mathrm{7.5}$ with $\mathrm{NaHCO}_{3}$ and lactonic material was extracted with ethyl acetate $(6 \times 100 \mathrm{ml}$.). The dry weight of the extracted material was $2.80 \mathrm{~g}$. A portion (1:231 g.) was heated with $N \mathrm{NaOH}\left(15 \mathrm{ml}\right.$.) at $100^{\circ}$ for $1 \mathrm{hr}$., the solution evaporated to dryness and the residual solid heated to $97^{\circ}$ with acetic anhydride $(30 \mathrm{ml}$.) for $1 \mathrm{hr}$. Excess acetic anhydride was then removed under reduced pressure and the acetylated material was treated with thionyl chloride $(45 \mathrm{ml}$.) at room temperature for $1 \mathrm{hr}$; ; excess of the reagent was then removed under reduced pressure. The residue was taken up in dry pyridine $(10 \mathrm{ml})$, freshly prepared $\beta$-alanine ethyl ester $(6 \mathrm{~g}$.$) added and the mixture left at room temperature for$ $1 \mathrm{hr}$., after. which the pyridine was removed under reduced pressure. The residual material was taken up in water (100 ml.), acidified to $p \mathrm{H} 1$ with $\mathrm{H}_{2} \mathrm{SO}_{4}$ and extracted with ethyl acetate $(6 \times 100 \mathrm{ml}$.$) . On evaporation the extracts$ yielded a brown oil which was hydrolysed by standing for $1 \mathrm{hr}$. at room temperature in alcoholic $\mathrm{NaOH}(2 \mathrm{~g}$. $\mathrm{NaOH}$ in $70 \mathrm{ml}$. ethyl alcohol). Excess alkali was neutralized with alcoholic $\mathrm{HCl}$ and, after removal of $\mathrm{NaCl}$ by filtration, the solution was evaporated, leaving a brown oil. The results of the biological test on this material together with the tests on the lactone fraction and the original liver filtrate factor concentrate are recorded in Table 2 below.

\section{Biological tests}

The method used for the estimation of liver filtrate factor differed from that previously described [Edgar et al. 1938] only in that crystalline synthetic vitamin $B_{6}$ was used as a supplement instead of a liver or yeast fuller's earth eluate containing that vitamin. The young rats received our cooked starch diet and as

Table 2. Growth response of rats receiving, as sources of B-vitamins, aneurin, riboflavin and vitamin $B_{6}$, to calcium d-pantothenate, to the lactone fraction of hydrolysed liver filtrate factor and to that fraction coupled with $\beta$-alanine

Average weekly wt. increase in $\mathrm{g}$. of groups during

2 weeks subsequent

Daily supplement given

\section{No. of}

None

1 rat day dose liver filtrate factor

$100 \mu \mathrm{g}$. Ca $d$-pantothenate

$50 \mu \mathrm{g}$. Ca $d$-pantothenate

$25 \mu \mathrm{g}$.Ca $d$-pantothenate

$100 \mu \mathrm{g}$. Ca $d$-pantothenate +1 rat day dose liver

filtrate factor

$0.98 \mathrm{mg}$. lactone fraction*

$1.96 \mathrm{mg}$. lactone fraction

$0.98 \mathrm{mg}$. lactone fraction coupled with $\beta$-alanine to giving

supplement

$6 \cdot 2$,

$17 \cdot 8,15$

14,17

18,16

6,6

20,17

$8,8 \cdot 5$

7,3

16,14

* Corresponds to 1 rat day dose of unhydrolysed concentrate. 
sources of B-vitamins each animal was given daily 10-15 $\mu \mathrm{g}$. aneurin, $50 \mu \mathrm{g}$. riboflavin and $10 \mu \mathrm{g}$. vitamin $B_{6}$. After 2-3 weeks on this diet the growth rate of the animals had decreased to about $6 \mathrm{~g}$. per week, and at this stage the test doses were given; when an active dose of liver.filtrate factor was supplied the growth rate of the animals increased to $15-20 \mathrm{~g}$. per week. We have continued to find the growth response on addition of liver filtrate factor so constant that reliable results were obtained when only two animals were employed for a single test material; where practicable, however, we have in most cases given the test materials to more than two animals.

The results of tests on relevant materials are given in Table 2. The amount of calcium $d$-pantothenate at our disposal was limited and permitted of only one animal being tested on the 25 and $50 \mu \mathrm{g}$. daily dose levels. The growth rates observed in these animals indicate, however, that the rat day dose of this factor is $>25 \mu \mathrm{g}$. and is probably about $50 \mu \mathrm{g}$.

\section{$\gamma: \delta$-Dihydroxyvaleryl- $\beta$-alanine methyl ester}

This was prepared by condensing allylacetyl chloride and $\beta$-alanine ethyl ester to give allylacetyl- $\beta$-alanine ethyl.ester which was hydrolysed to allylacetyl$\beta$-alanine. The latter was then oxidized in neutral solution with barium permanganate to $\gamma: \delta$-dihydroxyvaleryl- $\beta$-alanine which was isolated as the methyl ester. Freshly prepared $\beta$-alanine ethyl ester (11 g.) in dry pyridine $(30 \mathrm{ml}$.) was treated at $0^{\circ}$ with allylacetyl chloride $(11 \mathrm{~g}$.) and the reaction mixture heated to $90^{\circ}$ for $16 \mathrm{hr}$. The solid mass formed on cooling was extracted with ether and, after removal of the ether, the residue was acidified with $N \mathrm{HCl}(20 \mathrm{ml}$.$) and$ the crude allylacetyl- $\beta$-alanine ethyl ester isolated with $\mathrm{CHCl}_{3}$. $\mathrm{Hydrolysis} \mathrm{of}$ this to the free acid was accomplished by letting it stand at room temperature with occasional shaking for $1 \mathrm{hr}$. with $\mathrm{N} \mathrm{NaOH}(86 \mathrm{ml}$.) followed by neutralization with $N \mathrm{HCl}(86 \mathrm{ml}$.). The solution was evaporated under reduced pressure, the residue extracted with absolute alcohol and the extract evaporated. The product was dissolved in acetone and filtered from traces of $\beta$-alanine; evaporation yielded allylacetyl- $\beta$-alanine $(6 \cdot 9 \mathrm{~g}$.) which after recrystallization from benzene-light petroleum had M.P. $70^{\circ}$. (Found: C, 55.8; H, 7.5; N, 8.4\%; $\mathrm{C}_{8} \mathrm{H}_{13} \mathrm{O}_{3} \mathrm{~N}$ requires $\mathrm{C}, 56 \cdot 1 ; \mathrm{H}, 7 \cdot 7 ; \mathrm{N}, 8 \cdot 2 \%$.) A portion of this material $(6 \cdot 23 \mathrm{~g}$. was neutralized with $\mathrm{Ba}(\mathrm{OH})_{2}$ solution and dissolved in water $(600 \mathrm{ml}$.); a solution of barium permanganate $\left(6 \cdot 79 \mathrm{~g}\right.$. of $98 \% \mathrm{Ba}\left(\mathrm{MnO}_{4}\right)_{2}$ in $\left.600 \mathrm{ml} . \mathrm{H}_{2} \mathrm{O}\right)$ was added with stirring during $1 \mathrm{hr}$. The precipitated manganese dioxide was filtered off and $\mathrm{Ba}$ ions were removed by $\mathrm{H}_{2} \mathrm{SO}_{4}$. Evaporation in vacuo yielded a yellow oil which was extracted with absolute alcohol. The syrupy $\gamma: \delta$-dihydroxyvaleryl- $\beta$-alanine obtained on evaporation of the alcohol failed to crystallize and attempts to obtain a solid benzyl-thiuronium derivative were unsuccessful.

The crude material was therefore dissolved in alcohol, treated with diazomethane and the resulting methyl ester purified by molecular distillation. $\gamma: \delta$-Dihydroxyvaleryl- $\beta$-alanine methyl ester distilled at $80-90^{\circ} / 10^{-5} \mathrm{~mm}$. as a colourless syrup which subsequently set to a hygroscopic crystalline mass M.P. $48-49^{\circ}$. (Found: $\mathrm{C}, 50 \cdot 2 ; \mathrm{H}, 7.9 ; \mathrm{N}, 6.2 \% ; \mathrm{C}_{9} \mathrm{H}_{17} \mathrm{O}_{5} \mathrm{~N}$ requires $\mathrm{C}, 49 \cdot 3$; $\mathrm{H}, 7 \cdot 8 ; \mathrm{N}, 6.4 \%$.)

\section{SUMmaRY}

1. Liver filtrate factor has been shown to be identical with pantothenic acid.

2. Evidence is presented that the factor in liver extracts which is neither adsorbed by fuller's earth nor extracted from acid aqueous solution by amyl 
alcohol is a biological entity (factor $\beta$ ) and that a third unidentified factor $(\gamma$ ) is present in acid-autoclaved whole extract of liver.

3. A synthesis of $\gamma: \delta$-dihydroxyvaleryl- $\beta$-alanine methyl ester is described.

The authors wish to thank the Department of Scientific and Industrial Research for a Maintenance Allowance held by one of them (R. H.S.) and gratefully acknowledge gifts of liver extracts from Glaxo Laboratories Ltd., of vitamin $B_{6}$ from Merck and Co., Inc., and of riboflavin from Roche Products, Ltd.

\section{REFERENCES}

Babcock \& Jukes (1940). J. biol. Chem. 133, v.

Black, Frost \& Elvehjem (1940). J. biol. Chem. 132, 65.

Edgar, El Sadr \& Macrae (1938). Biochem. J. 32, 2200.

El Sadr, Hind, Macrae, Work, Lythgoe \& Todd (1939). Nature, Lond., 144, 73.

Hitchings \& Subbarow (1939). J. Nutrit. 18, 265.

Hoffer \& Reichstein (1939). Nature, Lond., 144, 72.

Jukes (1939). J. Amer. chem. Soc. 61, 975.

'Kringstad \& Lunde (1939). Hoppe-Seyl. Z. 261, 110.

Macrae, Todd; Lythgoe, Work, Hind \& El Sadr (1939). Biochem. J. 33, 1681.

Mohammad, Emerson, Emerson \& Evans (1940). J. biol. Chem. 133, 17.

Oleson, Woolley \& Elvehjem (1939). Proc. Soc. exp. Biol., N.Y., 42, 151.

Subbarow \& Hitchings (1939). J. Amer. chem. Soc. 61, 1615. \& Rane (1939). J. Amer. chem. Soc. 61, 1616.

Weinstock, Mitchell, Pratt \& Williams (1939). J. Amer. chem. Soc. 61, 1421.

Williams \& Major (1940). Science, 91, 246.

Truesdale, Weinstock, Rohrmann, Lyman \& McBurney (1938). J. Amer. chem. Soc. 60, 2719.

Weinstock, Rohrmann, Truesdale, Mitchell \& Meyer (1939). J. Amer. chem. Soc. 61, 454.

Woolley, Waismann \& Elvehjem $(1939,1)$. J. Amer. chem. Soc. 61, 977. $(1939,2)$. J. biol. Chem. 129, 673. 